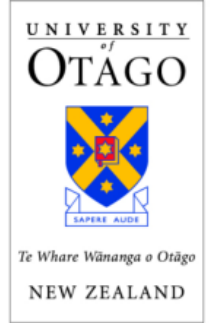

University of Otago

Economics Discussion Papers

School of Business

No. 1113

Te Kura Pakihi

September 2011

\title{
Due diligence, research joint ventures, and incentives to innovate*
}

\author{
Simona Fabrizi ${ }^{\dagger}$ \\ Massey University \\ Steffen Lippert ${ }^{\ddagger}$ \\ University of Otago
}

\footnotetext{
*We would like to thank Patrick Rey for his many helpful comments. We are grateful for the helpful comments provided by two anonymous referees, Uri Benzion, Gary Biglaiser, Francis Bloch, Antonio Cabrales, Nisvan Erkal, Rosemary Humberstone, Yvan Lengwiler, Tobias Lindqvist, Joanna PoyagoTheotoky, Carlo Scarpa, Konrad Stahl, and José María Usategui. Additionally, we thank the conference and seminar participants at Toulouse, Keele, Massey, the 2005 CEPR/IUI Conference on Innovation, Ownership and Competition in Vaxholm, the 2005 EEA meeting in Amsterdam, the XXI Jornadas de Economía Industrial (JEI2005) in Bilbao, the 2006 ASSET meeting in Rethymnon, and the 28th Australasian Economic Theory Workshop (AETW2010) in Melbourne. This work was supported by CEPR (RTN/CPIM funds to Lippert) and the Royal Society of New Zealand (Marsden Grant MAU0804 to Fabrizi and Lippert).

†School of Economics and Finance (Albany) and Social Innovation and Entrepreneurship Research Centre, Massey University, PB 102 904, NSMC, 0745 Auckland, New Zealand, and Centre for Mathematical Social Sciences, University of Auckland. Email: s.fabrizi@massey.ac.nz

‡Corresponding author. Department of Economics, University of Otago, P.O. Box 56, Dunedin 9016, New Zealand, Social Innovation and Entrepreneurship Research Centre, Massey University, and Centre for Mathematical Social Sciences, University of Auckland. Email: steffen.lippert@otago.ac.nz
} 


\begin{abstract}
The decision to cooperate within R\&D joint ventures is often based on 'expert advice.' Such advice typically originates in a due diligence process, which assesses the $R \& D$ joint venture's profitability, for example, by appraising the achievability of synergies. We show that if the experts who advise the owners considering forming an R\&D joint venture are also responsible for $R \& D$ efforts, they can have incentives to withhold information about the extent of those synergies. Owners optimally react by reducing the incentives to innovate in low-value projects developed within $R \& D$ joint ventures and in high-value projects developed within competing research organizations.
\end{abstract}

JEL codes: D82, D86, L5, L24, O31, O32, O38.

Keywords: Research and development, due diligence, experts' advice, joint venture, synergies, asymmetric information, moral hazard, information withholding (concealing) and revelation. 


\section{Introduction}

Firms that are considering acquiring competitors, merging, or even entering strategic alliances will typically engage in a due diligence process aimed at assessing the costs and benefits of these acquisitions, mergers, or strategic alliances. To integrate the different perspectives and to utilize the expertise within the due diligence team, firms often include operating managers in this process. ${ }^{1}$ The due diligence process that firms perform in view of forming research and development (R\&D) joint ventures is no exception to this practice. Owners frequently rely to their executing researchers' assessments. These researchers are often the best, if not the only, experts who possess profound knowledge about the R\&D projects to be executed. Given the importance of the executing researchers' expert advice to the due diligence process, we analyze how relying on that advice during the formation of $R \& D$ joint ventures affects the contracts that are offered to the researchers, the $R \& D$ efforts of the researchers, the R\&D organization chosen chosen, and ultimately, the intensity of $R \& D$ that is implemented.

When firms organize their $\mathrm{R} \& \mathrm{D}$ in a joint venture, they regularly incur organizational costs that would not be incurred had they conducted their R\&D on their own. For example, incentivizing researchers to perform in a new, more complicated organizational environment is often more costly because successes and failures are no longer easily attributable to one's own R\&D team. These increased information asymmetries in R\&D joint ventures affect owners and researchers asymmetrically. As a result, the owners' and researchers' preferences regarding the decision to cooperate or to compete in $\mathrm{R} \& \mathrm{D}$ are not always aligned. Given this misalignment of interests, researchers may have incentives to withhold information about the relative profitability of competing and cooperative $R \& D$ during the due diligence process. Our contribution is to show the conditions under which this is the case and that, to induce

\footnotetext{
${ }^{1}$ Jemison and Sitkin (1986) provide examples of this practice and write, "For example, Sam Ginn, vice chairman of the Pacific Telesis Group, involves in negotiations the operating manager who would be responsible for the new subsidiary. At PacTel, the arguments justifying the acquisition form the basis of the plan on which the target company will be run and against which the manager will subsequently be evaluated" (page 109).
} 
the researchers to reveal their private information, firms should distort their innovation intensities away from the intensities that they would have implemented had they been able to directly assess the relative profitability of the R\&D joint venture without including the researchers in the due diligence process. We also examine the conditions under which this distortion implies a reduction in the implemented R\&D intensities. Finally, we argue that involving operating managers in the due diligence for mergers and acquisitions (M\&As) has the same consequences described for the formation of $R \& D$ joint ventures.

Government programs supporting the formation of $R \& D$ joint ventures affect the relative payoffs of the research organizations involved, but they do not directly affect the payoffs of the researchers who are effectively conducting the research. For this reason, these programs impact the conflict between researchers and owners as well as the incentives given to researchers to exert efforts in their R\&D activities. Our results suggest that for innovation projects targeting large markets, subsidies reduce the incentives to innovate in competing R\&D projects, but they increase the incentives to innovate within $R \& D$ joint ventures. In contrast, for innovation projects targeting small to intermediate-sized markets, government support for R\&D joint ventures increases the innovation intensity in competing R\&D projects and decreases the innovation intensity within R\&D joint ventures.

We contribute to the literature in three ways. First, we contribute to the rich literature on $R \& D$ joint venture formation. This literature studies the justifications for forming R\&D joint ventures as well as their impact on social welfare. It finds that $R \& D$ joint ventures are often privately and socially desirable because they enable participating firms to internalize externalities and spillovers, to share $R \& D$ costs and reduce $R \& D$ effort duplication, and to use complementarities and synergies (see d'Aspremont and Jacquemin, 1988, and Kamien, Muller, and Zhang, 1992, for seminal contributions, upon which most of the R\&D joint venture formation literature is based; also see Caloghirou, Ioannides, and Vonortas, 2003, for an excellent survey). In contrast to this literature, we open the black box of firms pondering cooperative $R \& D$ and identify how information asymmetries within firms affect 
the final decision to cooperate as well as the incentives to innovate offered to researchers. This allows us to pinpoint the impact of the costs of the formation and operation of R\&D joint ventures coming from information asymmetries within the firms and the R\&D joint ventures - costs that the literature typically ignores. To our knowledge, only Falvey et al. (2006) and Fabrizi and Lippert (2010) take into account additional costs within R\&D joint venture formation models. While Falvey et al. (2006) model the impact of coordination costs on the private and social desirability of R\&D joint ventures, Fabrizi and Lippert (2010) focus on the consequences of additional information asymmetries in $R \& D$ joint ventures for competition policy. Building on that model, we study the implications of involving the executing researchers in the due diligence process.

Second, we contribute to the literature on expert advice. For example, Crawford and Sobel (1982) and the rich subsequent literature focus on strategic information transmission by an expert interested in biasing a decision maker's action, which determines the welfare of both. Ambrus, Azevedo, and Kamada (2010) model such strategic information transmission in a hierarchy. Goltsman et al. (2009) and Ivanov (2010) consider the impact of a mediator between such an expert and the decision maker. Typically, in these models, the expert's bias is generic and exogenously given. In contrast, in our model, the expert's bias is specific to the situation and endogenous. In this situation, the decision maker chooses the organizational structure within which to carry out a project with the expert as the operating manager. We show that the expert's ability to strategically withhold information affects not only the decision maker's organizational choice but also the incentives given to the expert for carrying out the project. Similarly to Green and Laffont (1982), we have partially verifiable information: the synergies available in an $R \& D$ joint venture become verifiable only if an $R \& D$ joint venture is chosen. In line with their result, in our model, the decision maker may find it optimal not to establish incentives for truth telling in all instances. By considering (partially) verifiable information, we also relate to earlier contributions to the literature on persuasion games (see Grossman (1981), Milgrom (1981) or Milgrom and Roberts (1986)). In these 
models, the expert can hide hard information (for example on the quality of his products) and the decision maker assumes that any missing information is likely to be unfavorable to the expert. Consequently, the expert will voluntarily reveal all favorable information, which leads to full disclosure. As in Shin (1994), in our model, full disclosure fails because there is uncertainty about whether the expert knows the true state.

Third, our setup allows us to contribute to the literature that studies how a firm's competitive environment affects the optimal incentives to exert an effort in the invention of new products, the reduction of production costs, or the selling of a product. Within this literature, several studies highlight that competition affects managerial incentives positively. Competition offers a yardstick to the shareholders because the firm's performance can be measured against that of its close competitors, and it enables relative performance evaluation (Celentani and Loveira, 2006) by providing informative signals that must be considered in the contracting between principals and agents (Holmström, 1979 and 1982). Competition offers insurance to risk-averse managers by reducing the impact of exogenous (demand or cost) shocks, thus increasing incentives (Rey and Tirole, 1986). It may improve incentives to the management in firms with poor governance structures to adopt new technologies through the threat of bankruptcy (Aghion, Dewatripont, and Rey, 1997). We show that in situations in which firms can cooperate and base their decision to cooperate on contributions by the operating managers, the impact can go both ways: we find that support for cooperative R\&D may have a positive effect, but it may also have a negative effect on the researchers' incentives to innovate.

\section{Model setup}

Two firms, $i$ and $-i$, follow a product innovation project that targets a new market. Each firm $i$ has an owner, who we also refer to as a principal, and employs one researcher. This researcher, who we also refer to as the agent, and who we also call $i$, conducts the innovation project. The principals must decide whether to conduct the project standalone $(S)$ or to 
conduct the research project jointly within a new entity: the research joint venture $(J)$.

In a stand-alone setting, $(S)$, if only one of the firms succeeds at conducting the project, it will be a monopolist with its brand in the product market. We denote the monopolist's profits by $\pi$ and normalize the unsuccessful firm's profit to zero. If, however, both firms' projects succeed, then the brands of the two firms compete in a duopoly. Consumers perceive these two brands as differentiated; a parameter $\alpha \in[0,1 / 2]$, such that each duopolist earns $\alpha \pi$, captures the extent of this perceived differentiation. ${ }^{2}$ The lower bound, $\alpha=0$, corresponds to the two firms competing in prices with homogenous products, and the upper bound, $\alpha=\frac{1}{2}$, implies that, while the brands of the product are differentiated, consumers perceive them to be sufficiently close substitutes.

In a research joint venture setting, $(J)$, we assume an exogenously determined sharing rule, according to which the costs of a joint project are shared equally between the two firms. Following a joint venture success each firm earns duopoly profits, $\alpha \pi$. We normalize the product market profits of firms participating in an unsuccessful $R \& D$ joint venture to zero.

The process of developing new products is typically uncertain and, in contrast to much of the R\&D literature, ${ }^{3}$ our model accounts for this uncertainty. Each project's success depends on the efforts of the agents assigned to its execution. Additionally, in an R\&D joint venture

\footnotetext{
${ }^{2}$ The assumption $\alpha \in[0,1 / 2]$ implies that it is profitable for one firm to buy out the other one even if one brand of the product has to be discontinued. Suppose that we modeled the product market interaction as the price competition between two firms with differentiated products, constant unit costs, and linear demands such that $p_{i}=a-q_{i}-\gamma q_{-i}$, where $p_{i}$ and $q_{i}$ are firm $i$ 's price and quantity sold, $a$ is the highest willingness to pay, and $\gamma$ is a differentiation parameter. In this case, the restriction $\alpha \in\left[0, \frac{1}{2}\right]$ would imply that the products are sufficiently close substitutes that correspond to a sufficiently high $\gamma$. In this model, $\alpha \in\left[0, \frac{1}{2}\right] \Leftrightarrow \gamma \in\left[\gamma_{\min }, 1\right]$ with $\gamma_{\min }=1+\frac{(-9+2 \sqrt{114})^{\frac{1}{3}}}{3^{\frac{2}{3}}}-\frac{5}{(3(-9+2 \sqrt{114}))^{\frac{1}{3}}} \approx .61$. If $\alpha=0$, we have the extreme of price competition with homogenous products among firms, that is, $\gamma=1$. However, we formulate profits from a more general perspective. If we modeled the product market interaction as the price competition between two firms with homogenous products, then $\alpha=\frac{1}{2}$ would correspond to perfect collusion and any value $\alpha \in] 0, \frac{1}{2}$ [ would correspond to some degree of partial collusion. Because the specific form of the product market interaction is not critical to the conflict of interest studied in this paper, that is, the conflict of interest between an informed researcher and an uninformed principal, we do not open the black box of product market interaction.

${ }^{3}$ See Chowdhury and Martin (2011) for a discussion, and Lippert and Fabrizi (2004, 2010) and Chowdhury and Martin (2011) for exceptions.
} 
success depends on the synergies between the agents. In particular, in a standalone setting, each $\mathrm{R} \& \mathrm{D}$ project within firm $i$ is conducted by agent $i$, whose effort we denote $e_{i} \in[0,1[$. We model the probability that a project developed within firm $i$ will succeed as $p_{i}(S)=e_{i}$. This formulation implies that the success of each individual firm's project is assumed to be independent of that of the other firm's project. In an R\&D joint venture setting, we assume that the R\&D project will be jointly conducted by the two agents employed by the firms. These agents will operate within a common facility that enables them to capture synergies. Accordingly, we assume that the project's probability of success is a function of the two agents' efforts, $e_{i}$ and $e_{-i}$, and of a random parameter $s \in[0,1]$, which captures the degree of synergy in the joint project. We assume that the synergies enhance the productivity of the agents in the development process. Specifically, higher synergies lead to a higher probability that any given efforts lead to the project's success. We define the probability of success in an R\&D joint venture as $p(J)=e_{i}+e_{-i}-(1-s) e_{i} e_{-i}$. We restrict our analysis to those effort levels that lead to a well-defined probability (that is, to $p(J) \in[0,1[$ ).

A synergy level of $s=0$ captures a setting in which the agents' successes are independent and $p(J)=e_{i}+e_{-i}-e_{i} e_{-i}$. In this case, the probability that researchers working in the same laboratory will succeed will be the same as the probability that researchers working in separate facilities will succeed. However, if $s>0$, the agents exploit the fact that they work in the same facility and, to some degree, coordinate their tasks. We assume that the degree to which the agents can coordinate their tasks - the degree of synergy - is exogenously given. This value cannot be manipulated by either agents or principals but is instead inherent to the technical characteristics of the project. For example, if a development process involves a large amount of tacit learning, the the agents will not be able to coordinate to a large extent, and $s$ will be low. Conversely, if the process does not involve significant tacit learning, then agents can can coordinate their tasks to a greater extent, and $s$ will be high. We assume that the synergies are ex-ante unknown because they are specific to each project's development process. However, the due diligence process allows researchers to identify the extent of these 
synergies. In our benchmark scenario, the synergies are public information, whereas in an alternative scenario, the agents conducting the due diligence process are able to conceal their findings.

The effort exerted by researchers in developing the product is assumed to be privately costly to them. We model the cost to researcher $i$ as $c_{i}\left(e_{i}\right)=\frac{1}{2} e_{i}^{2}$. For executing the project, each researcher $i$ receives transfer $t_{i}$ from the entity employing him. Each researcher $i$ 's

utility $U_{i}$ is additively separable between effort and money, $U_{i}=t_{i}-\frac{1}{2} e_{i}^{2}$. We assume that the researchers are assumed to be protected by limited liability. That is, the transfers $t_{i}$ made by the firms have to be non-negative in any state of the world. Although we assume that contracts contingent on the researchers' efforts cannot be written, We assume that the success of a research project is observable and verifiable. Thus, contracts contingent on the projects' successes can be written. In R\&D joint ventures, we assume that it is not possible to observe and verify each researcher's individual contribution to the success of the project, but only the success of the whole project. This simple assumption captures the idea that the cost of acquiring information is higher in more complex organizations than in less complex organizations. Finally, in any configuration, we assume that the researchers do not collude in their decisions regarding their effort levels. This assumption may capture that researchers do not observe each others' efforts. Alternatively, it may capture that researchers do not interact repeatedly and thus do not have a means of cooperating via an implicit contract.

We assume that the owners are risk-neutral. They offer contracts to the agents and decide whether to compete or cooperate in the R\&D projects to maximize their expected profits net of the researchers' rewards.

\section{Benchmark: Symmetric information on synergies}

In this section, we assume that owners and researchers have full information about the synergies attainable in the $R \& D$ joint venture. The owners decide to develop a product through an R\&D joint venture if the expected profit from doing so exceeds the expected profit 
that can be obtained through a standalone development process. Because the researchers' effort levels are not contractible, the contracts in standalone $R \& D$ are contingent on the observable and verifiable success of the respective project, whereas in R\&D joint ventures, the contracts are contingent on the success of the entire project.

\subsection{Stand-alone development}

Optimal contracts are designed such that, if firm $i$ 's project fails, then researcher $i$ receives a base wage $w_{i}^{S}$, whereas if the project succeeds, he receives not only the base wage but also a bonus $b_{i}^{S}$ in which where the superscript $S$ denotes standalone development. After accepting the contract, researcher $i$ chooses the effort level that maximizes his utility. He solves

$$
\max _{e_{i}}\left[w_{i}+e_{i} b_{i}-\frac{1}{2} e_{i}^{2}\right],
$$

which results in the incentive compatibility constraint $(I C), e_{i}=b_{i}$. Researcher $i$ accepts the contract if his expected utility from doing so exceeds that of his outside option, which we normalize to zero. This forms his individual rationality constraint $(I R)$. Furthermore, because the researchers are protected by limited liability $(L L), w_{i}$ has to be non-negative.

Firm $i$ 's maximization problem under stand-alone development is

$$
\begin{array}{lll}
\max _{w_{i}, b_{i}}\left[e_{i}\left(1-e_{-i}\right) \pi+e_{i} e_{-i} \alpha \pi-e_{i} b_{i}-w_{i}\right] & \\
\text { s.t. } & e_{i}=b_{i} & (I C) \\
& w_{i} \geq 0 & (L L) \\
& w_{i}+e_{i} b_{i}-\frac{1}{2} e_{i}^{2} \geq 0 . & (I R)
\end{array}
$$

The solution to this problem gives $w_{i}^{S}=0$ and $b_{i}^{S}=e_{i}^{S}=\frac{\pi}{2+(1-\alpha) \pi}$ as well as the

expected per firm profits $E \Pi^{S}=\left(\frac{\pi}{2+(1-\alpha) \pi}\right)^{2}$ and the expected utility of the researchers $E U^{S}=\frac{1}{2}\left(\frac{\pi}{2+(1-\alpha) \pi}\right)^{2}$

\subsection{Research joint venture}

If the project in the $\mathrm{R} \& \mathrm{D}$ joint venture fails, each researcher receives a base wage $w_{i}^{J}$, whereas if the project succeeds, each researcher receives not only a base wage $w_{i}^{J}$, but also a bonus 
$b_{i}^{J}$, where the superscript $J$ denotes joint R\&D. Researcher $i$ solves

$$
\max _{e_{i}}\left[w_{i}+\left(e_{i}+e_{-i}-(1-s) e_{i} e_{-i}\right) b_{i}-\frac{1}{2} e_{i}^{2}\right],
$$

which results in the new incentive compatibility constraint

$$
e_{i}=\frac{b_{i}\left((1-s) b_{-i}-1\right)}{(1-s)^{2} b_{i} b_{-i}-1} \quad \forall i \neq-i .
$$

The joint venture solves $\forall i \neq-i$,

$$
\begin{array}{ll}
\max _{w_{i}, w_{-i}, b_{i}, b_{-i}}\left[\left(e_{i}+e_{-i}-(1-s) e_{i} e_{-i}\right)\left(2 \alpha \pi-b_{i}-b_{-i}\right)-w_{i}-w_{-i}\right] \\
\text { s.t. } & e_{i}=\frac{b_{i}\left((1-s) b_{-i}-1\right)}{(1-s)^{2} b_{i} b_{-i}-1} \\
& w_{i} \geq 0 \\
& w_{i}+\left(e_{i}+e_{-i}-(1-s) e_{i} e_{-i}\right) b_{i}-\frac{1}{2} e_{i}^{2} \geq 0 .
\end{array}
$$

The first-order conditions for this maximization program with respect to $b_{i}$ are

$$
\begin{aligned}
\frac{\partial \Pi^{J}}{\partial b_{i}}=\left(2 \alpha \pi-b_{i}-b_{-i}\right)\left(\left(1+(1-s) e_{-i}\right)\right. & \left.\frac{\partial e_{i}}{\partial b_{i}}+\left(1+(1-s) e_{i}\right) \frac{\partial e_{-i}}{\partial b_{i}}\right) \\
& -\left(e_{i}+e_{-i}-(1-s) e_{i} e_{-i}\right)=0, \quad \forall i,-i,
\end{aligned}
$$

with $e_{i}=\frac{b_{i}\left((1-s) b_{-i}-1\right)}{(1-s)^{2} b_{i} b_{-i}-1}$ and $e_{-i}=\frac{b_{-i}\left((1-s) b_{i}-1\right)}{(1-s)^{2} b_{i} b_{-i}-1}$. The resulting base wage is $w_{i}^{J}=w_{-i}^{J}=w^{J}=$ 0 , and the optimal bonus in the symmetric solution is given by the standard solution to a third-degree polynomial:

$$
b_{i}^{J}=b_{-i}^{J}=b^{J}=-\frac{1}{(1-s)}+\frac{\phi}{(1-s)^{2} \sqrt[3]{18}}-\frac{\sqrt[3]{\frac{2}{3}}}{\phi},
$$

where

$$
\left.\phi=\left(18(1-s)^{3}+9(1-s)^{4} 2 \alpha \pi+\sqrt{3} \sqrt{(1-s)^{6}\left(4+27(2+(1-s) 2 \alpha \pi)^{2}\right.}\right)\right)^{1 / 3} .
$$

\subsection{Equilibrium organization}

Using these results, we now characterize the equilibrium organization of R\&D with nonobservable efforts. Plugging the solution for the optimal contract into the profit functions and the researchers' expected utility, it is possible to derive the $s$ and $\pi$ combinations under which owners and researchers, respectively, prefer an R\&D joint venture to stand-alone development. 
Proposition 1 With symmetric information on synergies in an REBD joint venture, owners prefer R\&D joint ventures to stand-alone R\&D for high monopoly profits and high synergies.

Proof. Proposition 1 follows from comparing the values obtained in sections 3.1 and 3.2.

There are four main effects at work: (1) a payoff externality effect, (2) a product-market competition effect, (3) a synergies effect, and (4) an information loss effect. First, in standalone $\mathrm{R} \& \mathrm{D}$, firms exercise a negative payoff externality on their competitor. If firm $i$ implements a larger effort, this decreases firm $-i$ 's expected profit. Firm $i$ does not take this into account in its decision; hence, there is room for improvement by making a joint decision of how much effort to exert within an $R \& D$ joint venture. Second, implementing an R\&D joint venture means that the firms' presence in the product market is perfectly correlated: either they compete in the product market or there is no firm in the market. This means that success in an $R \& D$ joint venture is not very valuable if competition in the product market is cutthroat. Third, in an R\&D joint venture, firms can achieve synergies; two stand-alone firms cannot. Fourth, R\&D joint ventures have the drawback of having to incentivize agents in a more complex environment.

Solving the negative payoff externality by means of an $R \& D$ joint venture is particularly valuable to the owners (1) if competition in a duopolistic product market is not overly fierce, (2) if the probability that both firms will succeed in competition is high, and (3) if the synergies achievable in the R\&D joint venture are high. Condition (1) holds if consumers perceive the two brands of the product as sufficiently differentiated, which is captured by a high $\alpha$. Condition (2) holds if the implemented effort levels and thus the implemented probabilities of success in a stand-alone firm are high, that is, if the monopoly profit $\pi$ is high. Condition (3) holds if $s$ is sufficiently large. Consequently, owners prefer R\&D joint ventures to stand-alone development as long as synergies, $s$, and monopoly profits, $\pi$, are sufficiently high and consumers perceive the two brands of the product as sufficiently differentiated, that is, $\alpha$ is sufficiently high. Because higher expected profits imply higher optimal implemented efforts and, therefore, higher information rents for the agents, both 
agents and owners prefer to solve the negative payoff externality in an R\&D joint venture for high synergies, high monopoly profits, and strong product differentiation.

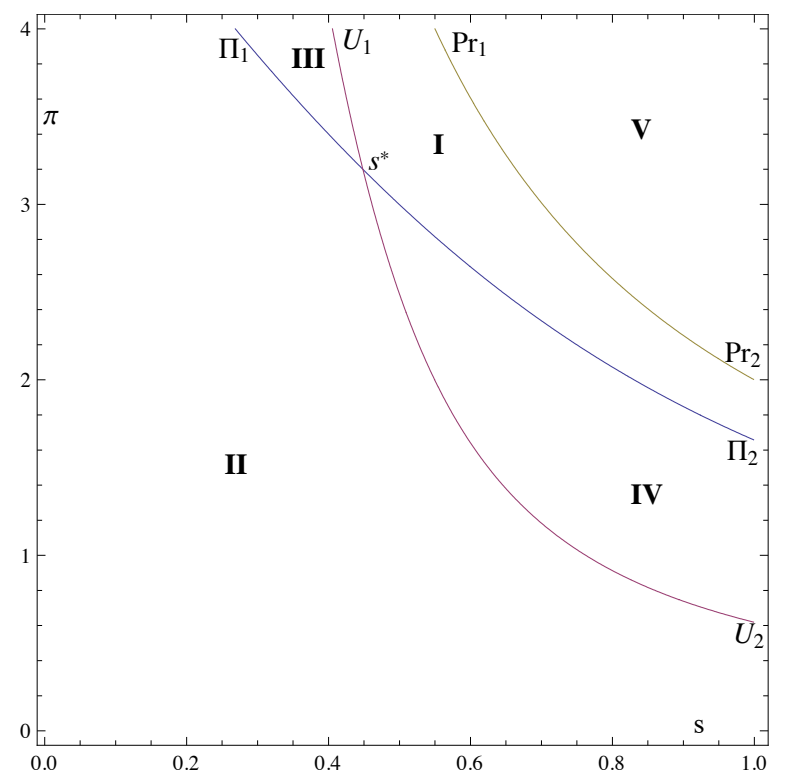

Figure 1: Comparison of stand-alone vs. joint development. Owners prefer R\&D joint ventures in areas I and III; researchers prefer R\&D joint ventures in areas II and IV. Only areas I, II, III, and IV, but not V, lead to a well-defined probability of success in an R\&D joint venture.

Figure 1 illustrates Proposition 1 by depicting both the owners' and the researchers' preferences for the organizational forms of development for $\alpha=\frac{1}{2}$. In this figure, the $\Pi_{1}$ - $\Pi_{2}$ - line represents the $(\pi, s)$ - combinations, for which each firm's expected profit from stand-alone development equals its expected profit from joint development. The $U_{1}-U_{2}-$ line represents the researchers' indifference curve between these two organizational forms. The $\mathrm{Pr}_{1}-\mathrm{Pr}_{2}$ - line corresponds to the $(\pi, s)$ - combinations, for which the probability of success under joint development would equal unity.

Definition 1 Using Figure 1 (case $\alpha=\frac{1}{2}$ ), define by $s^{*}$ the point at which $U_{1}-U_{2}$ and $\Pi_{1}-\Pi_{2}$ intersect and divide the $(\pi, s)$ space in five areas: area $I$, delineated by $U_{1}-s^{*}-$ $\Pi_{2}-P r_{2}-P r_{1}$, area II, to the left of the line $\Pi_{1}-s^{*}-U_{2}$, area III, delineated by $\Pi_{1}-s^{*}-U_{1}$, area $I V$, delineated by $U_{2}-s^{*}-\Pi_{2}$, and area $V$, delineated by $\mathrm{Pr}_{1}-\mathrm{Pr}_{2}$. 
In areas II and IV, the expected profits from stand-alone development are higher than those from joint development, and in areas I and III, the opposite holds. In areas II and III, researchers prefer stand-alone development, and in areas I and IV, the opposite holds. We exclude all $(\pi, s)$ - combinations above this line, area $\mathrm{V}$, because they would not lead to a well-defined probability of success in an R\&D joint venture.

Solving the payoff externality and having to incentivize agents in the more complex environment of an $R \& D$ joint venture introduces a wedge between the researchers' and the owners' preferences for the organizational form. For high values of the monopoly profit, $\pi$, the efforts implemented in a stand-alone situation are very high, such that the probability that both firms will succeed in developing the product and then have to compete/share the market is very high. Therefore, owners can gain from coordinating the implemented efforts under joint development. However, because this reduces the researchers' rents, for high monopoly profits and intermediate synergies, there are profit increasing $R \& D$ joint ventures that decrease the utility of the researchers compared to stand-alone R\&D. We depict this disagreement in area III in Figure 1. For lower values of $\pi$, this component does not carry as much weight, and the reduced ability to attribute a success or a failure to one of the researchers becomes relatively more important. The informational rents in a joint project would be very high, which is better for researchers and worse for owners. Hence, for low to intermediate monopoly profits and intermediate to high synergies, there are profit-decreasing R\&D joint ventures that would increase the researchers' utility compared to stand-alone R\&D. We depict this disagreement in area IV in Figure 1.

Proposition 2 summarizes these two conflicts, taking the example of $\alpha=\frac{1}{2}$.

Proposition 2 Consider the case of symmetric information on the synergies, s, and refer to the areas as introduced in Definition 1 and labeled in Figure 1.

1. In area III (for high monopoly profits and intermediate synergies), owners prefer RED joint ventures to stand-alone $R \mathscr{E} D$, whereas researchers prefer stand-alone RED to RESD joint ventures. 
2. In area IV (for lower monopoly profits and intermediate to high synergies), owners prefer stand-alone $R \mathscr{E} D$ to $R \mathscr{E} D$ joint ventures, whereas researchers prefer $R \mathscr{B} D$ joint ventures to stand-alone R\&D.

Proof. See Appendix A.

In Appendix A, we analyze degrees of product differentiation other than $\alpha=\frac{1}{2}$ and show that the two conflicts exist generally. We further demonstrate that, as products become more differentiated, the respective minimum synergies for which owners and researchers prefer $R \& D$ joint ventures over stand-alone development for any given monopoly profit become smaller.

\section{Asymmetric information on synergies}

In this section we analyze how optimal contracts change if the information about synergies in an $\mathrm{R} \& \mathrm{D}$ joint venture, which the researchers receive in the due diligence process, is not public. For this, assume that synergies are a random variable with $s \in\{\underline{s}, \bar{s}\}$, where $0 \leq \underline{s}<\bar{s} \leq 1$, and that the probability of high synergies, $\operatorname{Pr}(s=\bar{s})=\theta \in] 0,1[$, is common knowledge among researchers and owners.

With probability $q \in] 0,1[$, before the start of the project, researcher $i$ receives a perfectly informative private signal about the value of $s$. This signal is assumed to be hard (not falsifiable), but concealable. Assume the occurrence of the signal to be independent across researchers. ${ }^{4}$ The owners of each firm $i$ interview their researcher, who reports $m_{i} \in\{\emptyset, \underline{s}, \bar{s}\}$, where $\emptyset$ indicates that the researcher reports he did not learn anything about the synergies. Once one researcher reveals the signal, it can be relayed to the other firm's owners. Hence, it suffices that one researcher reveals his signal for both firms' owners to be informed. After forming an R\&D joint venture, which we assume to be irreversible, and before executing the project, the owners learn the true value of $s$, regardless of whether the agents sent a message

\footnotetext{
${ }^{4}$ These assumptions on the signals make it impossible for the principals to devise mechanisms that make the researchers reveal their private information without cost to the principals. See Crémer and McLean (1985) or Maskin and Riley (1985) for such mechanisms.
} 
indicating the extent of the synergies. If no R\&D joint venture is formed, the owners can only learn the value of $s$ from the agents, if the agents received a signal.

Hence, in stand-alone R\&D ventures, owners can make transfers to the researchers contingent (1) on the success or failure of the project and (2) on the researchers' messages. In an R\&D joint venture, owners can make the transfers to the researchers contingent (1) on the success or failure of the whole project, (2) on the researchers' messages, and (3) on the true synergies.

The timing of the model is now as follows:

1. Incentive contracts for the possible configurations are written.

2. Researchers receive a signal on possible synergies with probability $q$.

3. Researchers send a message $m \in\{\emptyset, \underline{s}, \bar{s}\}$.

4. Owners observe the messages and decide about the organizational form. This decision is irreversible.

5. Efforts are exerted and results obtained.

\subsection{Incentive constraints}

There are two types of incentive constraints: effort incentive constraints and revelation incentive constraints. The former are the usual incentive compatibility constraints, specifying the utility maximizing effort level for each bonus. The latter constraints are to ensure that the researchers reveal the signal if they received one.

\subsubsection{Effort incentive constraints}

There is no change in the effort incentive constraint compared to section 3 . Hence, in the stand-alone situation, researcher $i$ has incentive compatibility constraint

$$
e_{i}=b_{i}
$$


and in an R\&D joint venture, researcher $i$ has incentive compatibility constraint

$$
e_{i}=\frac{b_{i}\left((1-s) b_{-i}-1\right)}{(1-s)^{2} b_{i} b_{-i}-1} \quad \forall i \neq-i
$$

\subsubsection{Revelation incentives}

To derive revelation incentive constraints, we first exogenously fix the contracts to the level chosen under symmetric information on $s$, that is, to $w^{S}, b^{S}, w^{J}$, and $b^{J}$. Given these contracts, we then check which equilibria exist with respect to the researchers' choice to reveal a received signal.

Given $w^{S}, b^{S}, w^{J}$, and $b^{J}$, Proposition 2 identified two potential conflicts. For high monopoly profits, there are synergy levels for which owners prefer an R\&D joint venture, but researchers do not. Denote this as conflict 1. For low monopoly profits, there are synergy levels for which researchers prefer an R\&D joint venture, but owners do not. Denote this as conflict 2. Conflict 1 arises if the default organizational form is stand-alone; here, researchers could have an incentive to hide $s=\bar{s}$. Conflict 2 arises if the default organizational form is an R\&D joint venture; here, researchers could have an incentive to hide $s=\underline{s}$.

\subsection{Low expected synergies}

Assume a situation in which there are low expected synergies, such that conflict 1 arises.

Assumption 1 (1) For $\underline{s}$, both researchers and owners would prefer stand-alone under symmetric information on s. (2) $\theta$ is sufficiently low, such that REDD joint ventures would not be chosen without revelation of the signal.

Under Assumption 1, if $(\pi, \bar{s})$ is such that owners prefer stand-alone R\&D (in areas II and IV of Figure 1), they implement stand-alone development irrespective of the researchers' messages. Thus, researchers are indifferent between revealing and hiding the signal, and all $\left(m_{i}, m_{-i}\right)$ are equilibria. If $(\pi, \bar{s})$ is such that owners prefer an R\&D joint venture, owners will implement an R\&D joint venture if there is at least one researcher revealing the signal. 
If, in addition, $(\pi, \bar{s})$ is such that researchers also prefer an $\mathrm{R} \& \mathrm{D}$ joint venture (in area I of Figure 1), then researchers would reveal their signal and only $(\bar{s}, \bar{s})$ are equilibrium messages. If, however, $(\pi, \bar{s})$ is such that researchers prefer stand-alone development, each researcher's dominant strategy is to hide the signal, and only $(\emptyset, \emptyset)$ is an equilibrium. This happens in area III of Figure 1. Consequently, the symmetric information contracts would only implement an $R \& D$ joint venture if both the owners and the researchers prefer an $R \& D$ joint venture.

In an equilibrium in which researchers reveal their private information, the firms determine $w_{i}^{S p}\left(m_{i}\right), b_{i}^{S p}\left(m_{i}\right), w_{i}^{J p}\left(m_{i}, m_{-i}\right), b_{i}^{J p}\left(m_{i}, m_{-i}\right), i=1,2, i \neq-i$, in order to maximize their expected profits. The $p$ in the superscript (in addition to the previously introduced $S$ and $J$ ) denotes the "private information" of the researchers on the extent of the synergies $s$.

For researchers to reveal a signal in conflict 1, they have to be at least as well off as if stand-alone was implemented. Therefore, researchers have to receive a payment, in addition to their bonus and base wage, of $t_{i}\left(\bar{s}, m_{-i}\right) \geq E U_{i}^{S p}(\emptyset)-E U_{i}^{J p}\left(\bar{s}, m_{-i}\right)$, where the $E U_{i}^{S p}\left(m_{i}\right)$ stands for researcher $i$ 's expected utility in stand-alone after sending message $m_{i}$ and $E U_{i}^{J p}\left(m_{i}, m_{-i}\right)$ is his expected utility in an R\&D joint venture from sending $m_{i}$ if the other researcher sent $m_{-i}$. For each $s$, this utility difference is a function of the bonuses and the base wages to be paid in stand-alone development without revelation of the signal and in joint development. Hence, the researchers' revelation incentive constraint is a function of the relative expected utility in both organizational forms, which implies that it depends on the bonuses paid in each form. For this reason, it is optimal for owners to adjust these bonuses to incentivize the agents to give up their private information. Denoting the bonus of each researcher $i$ if he does not reveal a signal with $b_{i}^{S p}(\emptyset)$ and those in an R\&D joint venture if (1) both reveal a high signal, (2) only $i$ reveals a high signal, and (3) only $-i$ reveals a high signal with $(1) b_{i}^{J p}(\bar{s}, \bar{s}),(2) b_{i}^{J p}(\bar{s}, \emptyset)$, and (3) $b_{-i}^{J p}(\bar{s}, \emptyset)$, Proposition 3 shows the consequences of this insight.

Proposition 3 Under Assumption 1 (low expected synergies), if researchers receive a private 
signal on the size of synergies in an R\&D joint venture and the value of the monopoly profit is sufficiently high, the owners distort the optimal bonus to their researchers such that

1. $b_{i}^{S p}(\emptyset) \leq b_{i}^{S}$, inducing a lower probability of an innovation in stand-alone development compared to symmetric information over the synergies; and

2. $b_{i}^{J p}(\bar{s}, \bar{s}) \geq b_{i}^{J}, b_{i}^{J p}(\bar{s}, \emptyset) \geq b_{i}^{J}$, and $b_{-i}^{J p}(\bar{s}, \emptyset) \geq b_{-i}^{J}$, inducing a higher probability of an innovation in an $R \mathscr{E} D$ joint venture compared to symmetric information over the synergies.

For low values of the monopoly profit, the offered bonus stays the same as under symmetric information over the synergies.

Proof. See Appendix B.

Note that, as in Green and Laffont (1986), it may be optimal for the owner not to provide incentives for truthful revelation. This is the case close to the $\Pi_{1}-\Pi_{2}$ line in area III of Figure 1, where the transfer necessary to provide incentives for truthful revelation would have to be too large compared to the gains from the implementation of the "better" organizational environment. Close to the $U_{1}-U_{2}$ line in Figure 1, however, the transfer necessary to provide incentives for truthful revelation would have to be small, whereas the potential gain is large. In this case, the incentives to innovate given to the researchers in stand-alone (in an R\&D joint venture) are strictly smaller (strictly larger) if researchers obtain private information about synergies in the due diligence process than if they do not.

\subsection{High expected synergies}

Now, consider a situation in which there are high expected synergies, such that conflict 2 arises.

Assumption 2 (1) For $\bar{s}$, both researchers and owners would prefer an RED joint venture under symmetric information on s. (2) $\theta$ is sufficiently high, such that RED joint ventures would be chosen without revelation of the signal. 
Under Assumption 2, if $(\pi, \underline{s})$ is such that owners prefer an R\&D joint venture (in areas I and III in Figure 1), owners will implement an R\&D joint venture irrespective of the researchers' messages. Thus, all $\left(m_{i}, m_{-i}\right)$ are equilibria. If $(\pi, \underline{s})$ is such that owners prefer stand-alone development, owners will implement stand-alone development if there is at least one researcher revealing the signal. Additionally, if $(\pi, \underline{s})$ is such that researchers also prefer stand-alone development (in area II in Figure 1), then researchers would reveal their signal and only $(\underline{s}, \underline{s})$ are equilibrium messages. If, however, $(\pi, \underline{s})$ is such that researchers prefer an $R \& D$ joint venture, each researcher's dominant strategy is to hide the signal, and only $(\emptyset, \emptyset)$ is an equilibrium. This is the case in area IV in Figure 1. Consequently, the symmetric information contracts would only implement stand-alone if both the owners and the researchers preferred stand-alone.

In an equilibrium in which researchers reveal their private information, the firms choose $b_{i}^{S p}\left(m_{i}\right), w_{i}^{S p}\left(m_{i}\right), b_{i}^{J p}\left(m_{i}, m_{-i}, s\right)$, and $w_{i}^{J p}\left(m_{i}, m_{-i}, s\right)$ to maximize their expected profits. Once more, the $p$ in the superscript (in addition to the previously introduced $S$ and $J$ ) denotes the "private information" of the researchers on the extent of the synergies $s$. Note that the contracts for an $R \& D$ joint venture will be a function not only of the messages but also of the true synergies.

For researchers to reveal a signal in conflict 2, they have to be at least as well off as if an $R \& D$ joint venture were to be implemented. Therefore, researchers must receive a payment, in addition to their bonus and base wage, of $t_{i}\left(\underline{s}, m_{-i}, \underline{s}\right) \geq E U_{i}^{J p}\left(\emptyset, m_{-i}, \underline{s}\right)-E U_{i}^{S p}(\underline{s})$, where $E U_{i}^{J p}\left(m_{i}, m_{-i}, \underline{s}\right)$ represents the expected utility of a researcher who did not send a message if the synergies turn out to be $\underline{s}$ and the other researcher sent a message $m_{-i}$, and $E U_{i}^{S p}\left(m_{i}\right)$ represents the utility of researcher $i$ if he sent message $m_{i}$. This utility difference is a function of the bonuses and the base wages to be paid in an $R \& D$ joint venture without revelation of the signal and in stand-alone development. Because their revelation incentive constraint is a function of the relative expected utility in both organizational forms, it depends, once more, on the bonuses paid. Hence, it is optimal for owners to adjust 
these bonuses to incentivize the agents to give up their private information about synergies. Denoting the bonus of each researcher $i$ if he did not reveal a signal (but the other researcher did) with $b_{i}^{S p}(\emptyset)$, and the bonus in an R\&D joint venture if neither researcher revealed a high signal as $b_{i}^{J p}(\emptyset, \emptyset, \underline{s})$, Proposition 4 characterizes the consequences of this insight.

Proposition 4 Under Assumption 2 (high expected synergies), if researchers receive a private signal on achievable synergies in an RED joint venture and the value of the monopoly profit is intermediate, the owners distort the optimal bonus to their researchers such that

1. $b_{i}^{S p} \geq b_{i}^{S}$, inducing a higher probability of an innovation in stand-alone development compared to symmetric information over the synergies; and

2. $b_{i}^{J p}(\emptyset, \emptyset, \underline{s}) \leq b_{i}^{J}$, inducing a lower probability of an innovation in an $R \& D$ joint venture compared to symmetric information over the synergies.

For high and low values of the monopoly profit, the offered bonus remains the same as under symmetric information over the synergies.

Proof. See Appendix C.

Again, as in Green and Laffont (1986), it may be optimal for the owner not to provide incentives for truthful revelation. This is the case close to the $\Pi_{1}-\Pi_{2}$ line in area IV of Figure 1, where the transfer necessary to provide incentives for truthful revelation would have to be too large compared to the gains from the implementation of the better organizational environment. Close to the $U_{1}-U_{2}$ line in Figure 1, however, the transfer necessary to provide incentives for truthful revelation would have to be small, while the potential gain is large. In this case, the incentives to innovate given to the researchers in stand-alone (in an R\&D joint venture) are strictly larger (strictly smaller) if researchers obtain private information about synergies in the due diligence process than if they do not. 


\subsection{Summary of results}

Table 1 highlights the distortions to the incentives to innovate given to the researchers in stand-alone $R \& D$ and in $R \& D$ joint ventures if researchers receive private information on the synergies in an R\&D joint venture during the due diligence process. Bonuses are distorted such that agents are rewarded for disclosing signals that would change the owners' default organization, and they are punished for not disclosing signals that would have changed the owners' default organization.

\begin{tabular}{lcc}
\hline & Stand-alone & R\&D joint venture \\
\hline & & $b_{i}^{J p}(\bar{s}, \bar{s}) \geq b_{i}^{J}$ \\
Low expected synergies & $b_{i}^{S p}(\emptyset) \leq b_{i}^{S}$ & $b_{i}^{J p}(\bar{s}, \emptyset) \geq b_{i}^{J}$ \\
& & $b_{-i}^{J p}(\bar{s}, \emptyset) \geq b_{-i}^{J}$ \\
High expected synergies & $b_{i}^{S p} \geq b_{i}^{S}$ & $b_{i}^{J p}(\emptyset, \emptyset, \underline{s}) \leq b_{i}^{J}$ \\
\hline
\end{tabular}

Table 1: Distortions in the bonus structure induced by asymmetric information on $s$.

\section{Extension: Mergers and acquisitions}

Our analysis thus far has shown that if, during the due diligence, the researchers obtain private information on the synergies that can be achieved in an $R \& D$ joint venture, the firms' owners distort their incentives to innovate to elicit that private information. In this section, we argue that the main insights gained in that environment continue to hold if, instead, the two firms considered conducting out the research project in a merger, creating one firm with a multi-product offering. ${ }^{5}$ While our leading example in this section is that of an M\&A, studying this case would also provide insights into the mechanics of R\&D joint venture formation when the joint venture partners are able (and allowed) to collude in the product market ensuing from the joint venture but were not able (or were not allowed) to collude if they competed in stand-alone projects.

\footnotetext{
${ }^{5}$ We are grateful to an anonymous referee for pointing us in this direction.
} 
When firms decide on merging rather than forming an R\&D joint venture, three of the four effects described, the payoff externality effect, the synergies effect, and the information loss effect, still work the same way as in the formation of an R\&D joint venture.

We have shown for the case of R\&D joint venture formation that the owners' and the researchers' preferences over the organizational form are in conflict because two of these three effects, the payoff externality effect and the information loss effect, affect on researchers and owners differently. On the one hand, solving the payoff externality increases profits for owners because it allows owners to coordinate the implemented efforts, leading to a decrease in the equilibrium bonuses paid to the researchers. Hence, while solving the payoff externality increases payoffs for owners, it decreases the researchers' rents. In contrast, the information loss is detrimental to owners, but it increases the researchers' rents. Solving the profit externality has a larger impact in markets with higher (single-product) monopoly profits than in markets with lower monopoly profits, while the information loss effect is always present. Hence, if monopoly profits are high, for some degree of synergies, researchers prefer the owners not to solve the payoff externality, whereas owners prefer to do so. in contrast, solving the profit externality has a smaller impact in markets with smaller monopoly profits. Hence, if monopoly profits are low, for some degree of synergies, researchers would prefer owners to solve the payoff externality, whereas owners instead would prefer not to do so.

Because the payoff externality effect and the information loss effect are both present in the decision to merge, they induce the same types of conflicts when firms contemplate carrying out the research project in a merger between the two firms, creating one firm with a multi-product offering. Therefore, if researchers obtain private information on the synergies in the due diligence for an M\&A, the owners will distort the researchers' incentives to elicit that private information in an M\&A as they did in an R\&D joint venture.

The only effect that works differently in an M\&A than in an R\&D joint venture is the product-market competition effect. In an R\&D joint venture, the successful partners compete in the product market, whereas in an M\&A, they do not. This reverses the effect of product 
market competition on both owners and researchers. Solving the negative profit externality by means of an R\&D joint venture is especially profitable if competition in the product market is not too fierce, but solving it by means of an M\&A is especially profitable in the opposite case, that is, if competition in the product market is fierce. However, the change in the working of the product-market competition effect does not eliminate the conflicts arising from the payoff externality effect and the information loss effect. Therefore, the main results for M\&As are similar to the results for R\&D joint venture formation. For this reason, we feel that, for the sake of brevity, we should not reproduce the entire analytical presentation of the results for the case of an M\&A. ${ }^{6}$

\section{Conclusions}

It is common practice for firms considering entering into an $R \& D$ joint venture to engage in a due diligence process to assess the costs and benefits of the joint venture. Firms frequently involve researchers in that process to utilize their expertise. This paper examines the impact of that practice on the optimal incentives to innovate given to researchers.

We first show the conditions under which researchers have an incentive to withhold private information on the relative profitability of $R \& D$ joint ventures compared to competing R\&D projects. We argue that there are two reasons for researchers to withhold that information. On the one hand, in a joint venture, owners solve a negative payoff externality by implementing a lower effort than if they competed in their projects. This decreases the researchers' information rents. On the other hand, in a joint venture, owners incur a higher cost of giving incentives to the researchers because researchers now operate in a more complex environment. This increases the researchers' information rents. For high monopoly profits (for example, if the project targets a large market), the first effect prevails over the second, and researchers have an incentive to withhold information that would lead owners to form a joint venture. For low monopoly profits, the second effect prevails, and researchers

\footnotetext{
${ }^{6}$ These analytical results are available from the authors upon request.
} 
have an incentive to withhold information that would lead owners to compete with each other. These effects exist because, contrary to what is commonly assumed in the R\&D joint venture formation literature (see, for example, Kamien et al., 1992, and many contributions thereafter), it is not costless to realize the gains of an $R \& D$ joint venture. Often, joint structures are more complex and less transparent, leading to higher costs of incentivizing employees in general and researchers in particular.

Next, we show how the owners of the firms distort the incentives to innovate provided to their researchers in both $R \& D$ joint ventures and competing stand-alone $R \& D$ with the aim that the researchers will reveal their private information. We show that if there is a high profit attainable in the target market, incentives are distorted upwards in competing research and downwards in an $R \& D$ joint venture. Furthermore, we show that if there is a low profit attainable in the target market, incentives are distorted downwards in competing research and upwards in an $R \& D$ joint venture.

Our results indicate that increasing the accuracy of assessing possible $R \& D$ joint ventures by utilizing the expertise of the researchers responsible for the execution of $R \& D$ projects in the due diligence process comes at the expense of increasing the cost of implementing the profit-maximizing organizational form.

Finally, we argue that our insights hold if the firms contemplate conducting the R\&D project in a merged firm instead of in a joint venture.

\section{References}

[1] Aghion, P., Dewatripont, M., Rey, P., 1997. Competition, Financial Discipline and Growth. Review of Economic Studies 64, 825-852.

[2] Ambrus, A., Azevedo, E., Kamada, Y., 2010. Hierarchical cheap talk. Unpublished working paper. 
[3] Caloghirou, Y., Ioannides, S., Vonortas, N.S., 2003. Research Joint Ventures. Journal of Economic Surveys 17(4), 541-570.

[4] Celentani, M., Loveira, R., 2006. A simple explanation of the relative performance evaluation puzzle. Review of Economic Dynamics 9, 525-540.

[5] Chowdhury, S. M., Martin, S., 2011. Innovation Races with the Possibility of Failure. Unpublished paper presented at the 9th International Industrial Organization Conference.

[6] Crawford, V., Sobel, J., 1982. Strategic information transmission. Econometrica 50, $1431-1451$.

[7] Crémer, J., McLean, R., 1985. Optimal selling strategies under uncertainty for a discriminating monopolist when demands are interdependent. Econometrica 53, 345-361.

[8] d'Apresmont, C., Jacquemin, A., 1988. Cooperative and noncooperative R\&D in duopoly with spillovers. American Economic Review 78, 1133-1137.

[9] Fabrizi, S., Lippert, S., 2004. How much efficiency gains and price reductions to put as ingredients into an efficiency defense? Quanto Basta. UPV - DFAEII Working Paper 2004-04. Available at http://econpapers.repec.org/paper/ehudfaeii/200404.htm. Downloaded on July 29, 2011.

[10] Fabrizi, S., Lippert, S., 2010. On moral hazard and joint R\&D. Available at http://econpapers.repec.org/paper/keekerpuk/2007_2f03.htm. Downloaded on April 12, 2010.

[11] Falvey, R., Poyago-Theotoky, J., Teerasuwannajak, K., 2006. Coordination costs: a drawback for research joint ventures? Available at http://ideas.repec.org/p/lbo/lbowps/2006_3.html. Downloaded on March 19, 2010. 
[12] Goltsman, M.,Hoerner, J., Pavlov, G., Squintani, F., 2009. Mediation, arbitration and negotiation. Journal of Economic Theory 144(4), 1397-1420.

[13] Green, J.R., Laffont, J.-J., 1982. Partially verifiable information and mechanism design. Review of Economic Studies 53(3), 447-456.

[14] Grossman, S.J., 1981. The informational role of warranties and private disclosure about product quality. Journal of Law and Economics 24(3), 461-483.

[15] Holmström, B., 1979. Moral hazard and observability. Bell Journal of Economics 10, 74-91.

[16] Holmström, B., 1982. Moral hazard in teams. Bell Journal of Economics 13, 324-340.

[17] Ivanov, M., 2010. Communication via a strategic mediator. Journal of Economic Theory $145(2), 869-884$.

[18] Jemison, D.B., Sitkin, S.B., 1986. Acquisitions: the process can be a problem. Harvard Business Review 64(2), 107-110.

[19] Kamien, M., Muller, E., Zang, I., 1992. Research joint ventures and R\&D cartels. American Economic Review 82, 1293-1306.

[20] Maskin, E., Riley, J., 1985. Auction theory with private values. American Economic Review 75, 150-155.

[21] Milgrom, P., 1981. Good news and bad news: representation theorems and applications. Bell Journal of Economics 12(2), 380-391.

[22] Milgrom, P., Roberts, J., 1986. Relying on the information of interested parties. RAND Journal of Economics 17(1), 18-32.

[23] Rey, P., Tirole, J., 1986. The logic of vertical restraints. American Economic Review $76,921-939$. 
[24] Shin, H.S., 1994. News management and the value of firms. RAND Journal of Economics $25(1), 58-71$.

\section{Appendix}

\section{A Proof of Proposition 2}

Proof. We first give a proof for $\alpha=\frac{1}{2}$, then we show graphically that the results hold for all other $\alpha \in\left[0, \frac{1}{2}\right]$. Consider the highest value of $\pi$ for which $e_{i}^{S} \in[0,1]$ is $\pi=\frac{2}{\alpha}$. For any $\pi=\frac{2}{\alpha}, E U^{S}=E U^{J}$ if $s=0.405546$, and $E \Pi^{S}=\frac{1}{2} E \Pi^{J}$ if $s=0.268625$. As profits and utility in R\&D joint ventures are increasing in $s$, for $\pi=\frac{2}{\alpha}$ and $s \in(0.268625,0.405546)$, $E U^{S}<E U^{J}$ and $E \Pi^{S}>\frac{1}{2} E \Pi^{J}$. Next, for $\alpha=\frac{1}{2}, E U^{S}=E U^{J}$ and $E \Pi^{S}=\frac{1}{2} E \Pi^{J}$ for $\left(s^{*}, \pi^{*}\right)=(0.448442,3.19968)$. For continuity, there must be $s^{\prime}>s^{*}$ and $\pi^{\prime}<\pi^{*}$ such that $E U^{S}\left(s^{\prime}, \pi^{\prime}\right)<E U^{J}\left(s^{\prime}, \pi^{\prime}\right)$ and $E \Pi^{S}\left(s^{\prime}, \pi^{\prime}\right)>\frac{1}{2} E \Pi^{J}\left(s^{\prime}, \pi^{\prime}\right)$. Figure 2 shows the researchers' and owners' preferences over organizational forms for $\alpha \in\left\{\frac{1}{100}, \frac{1}{6}, \frac{1}{3}, \frac{1}{2}\right\}$. The conflicts of interest described in Proposition 2 are present for all of these values of $\alpha$, that is, for any degree of competition in the market.

\section{B Proof of Proposition 3}

Proof. Suppose first that the principal implements truthful revelation. With contracts that induce the researchers to reveal their signal if they received one, the expected profits are as follows. With probability $(1-q)^{2}$, no signal has been received by either researcher, and $E \Pi^{S p}(\emptyset)$. With probability $\left(1-(1-q)^{2}\right)(1-\theta)$, at least one researcher received $\underline{s}$, which he always has an incentive to reveal, and the expected profits are $E \Pi^{S p}(\underline{s})$. With probability $q^{2} \theta$, both researchers received $\bar{s}$. In the equilibrium in which they reveal their signals, both receive a transfer for revealing, and the expected profits per firm are $E \Pi^{J p}(\bar{s}, \bar{s})-$ $\left(E U^{S p}(\emptyset)-E U^{J p}(\bar{s}, \bar{s})\right)$. With probability $2 q(1-q) \theta$, one of the researchers received $\bar{s}$, and the other one did not receive a signal. In the equilibrium in which the researcher 

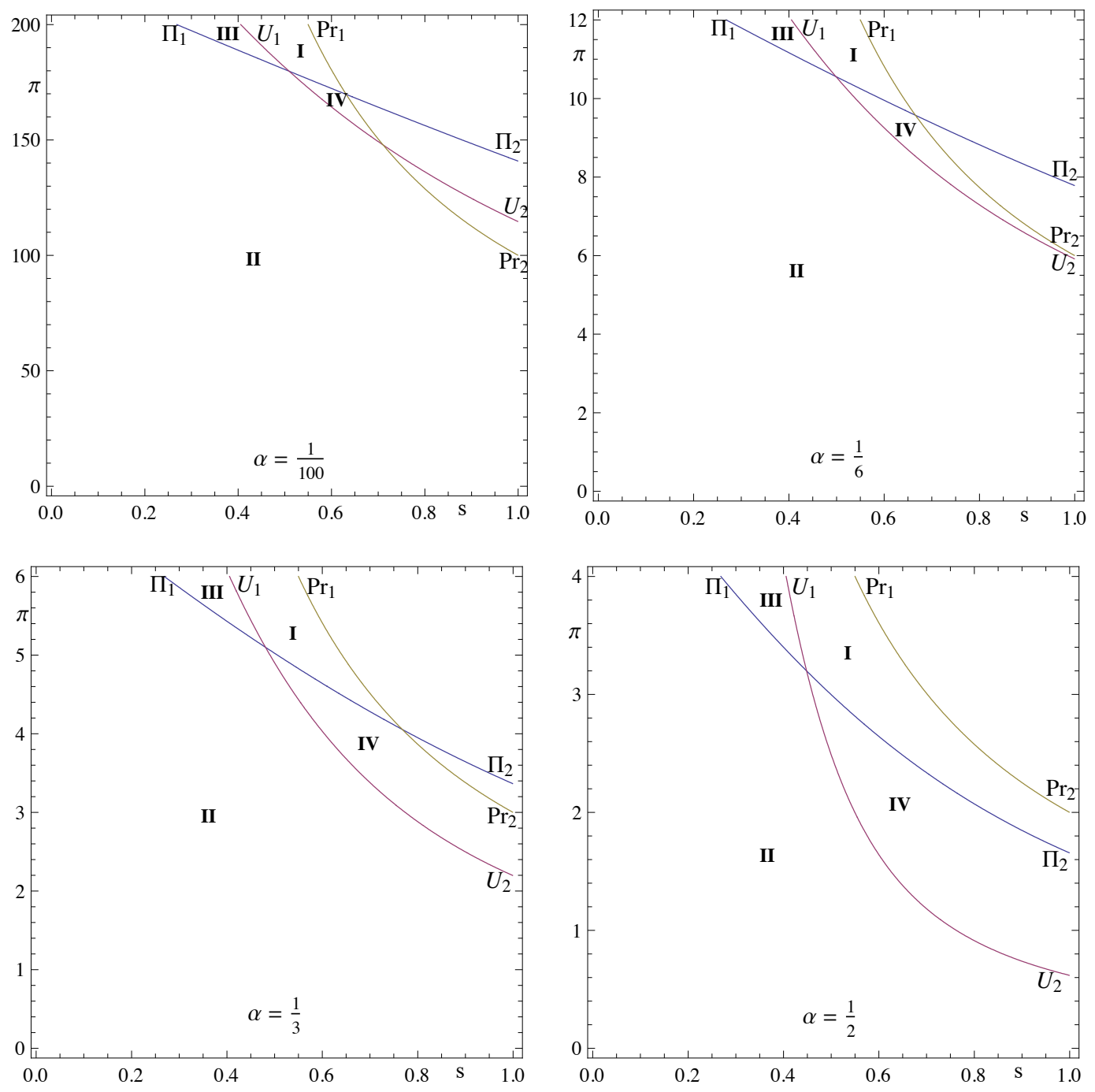

Figure 2: Comparison of stand-alone vs. R\&D joint venture for different degrees of competition. Owners prefer $R \& D$ joint ventures to the right of the $\Pi_{1}-\Pi_{2}-$ line; researchers prefer R\&D joint ventures to the right of the $U_{1}-U_{2}-$ line. Only $(\pi-s)-$ combinations to the left of $P r_{1}-P r_{2}$ lead to a well-defined probability of success in an R\&D joint venture. $\alpha=\frac{1}{100}$ is close to perfect price competition; $\alpha=\frac{1}{2}$ signifies that it is just profitable to merge the two competitors if the merged entity had to drop one of the two differentiated products. 
who received the signal reveals it, that researcher receives a transfer for revealing, and the expected profits per firm are $E \Pi^{J p}(\bar{s}, \emptyset)-\frac{1}{2}\left(E U^{S p}(\emptyset)-E U^{J p}(\bar{s}, \emptyset)\right)$. Therefore, each firm's expected profit is

$$
\begin{aligned}
& E \Pi=(1-q)^{2} E \Pi^{S p}(\emptyset)+\left(1-(1-q)^{2}\right)(1-\theta) E \Pi^{S p}(\underline{s})+ \\
& \begin{aligned}
q^{2} \theta\left(E \Pi^{J p}(\bar{s}, \bar{s})-\left(E U^{S p}(\emptyset)-E U^{J p}(\bar{s}, \bar{s})\right)\right)+ \\
2 q(1-q) \theta\left(E \Pi^{J p}(\bar{s}, \emptyset)-\frac{1}{2}\left(E U^{S p}(\emptyset)-E U^{J p}(\bar{s}, \emptyset)\right)\right) .
\end{aligned}
\end{aligned}
$$

The restrictions to be fulfilled are the limited liability constraints, the researchers' participation constraints, and the effort incentive compatibility constraints.

Each firm's first-order condition with respect to the bonus of researcher $i$ if he does not reveal a signal, $b_{i}(\emptyset)$, can be written as

$$
\frac{\partial E \Pi}{\partial b_{i}(\emptyset)}=\left(1-b_{-i}(\emptyset)\right) \pi+b_{-i}(\emptyset) \frac{\pi}{2}-2 b_{i}(\emptyset) \underbrace{-\frac{q}{(1-q)^{2}} \theta \frac{\partial E U^{S p}(\emptyset)}{\partial b_{i}(\emptyset)}}_{\leq 0}=0 .
$$

Denote the solution to this problem by $b_{i}^{S p}(\emptyset)$. Under symmetric information on $s$, the first order condition was

$$
\frac{\partial E \Pi^{S}}{\partial b_{i}}=\left(1-b_{-i}\right) \pi+b_{-i} \frac{\pi}{2}-2 b_{i}=0
$$

Thus, with private information on synergies, the incentives given to the researchers in standalone development are lower than those given with symmetric information, $b_{i}^{S p}(\emptyset)<b_{i}^{S}$.

Furthermore, each firm's first-order conditions with respect to the bonuses of the researchers in an R\&D joint venture after $m_{i}=m_{-i}=\bar{s}$ can be written as

$$
\begin{aligned}
& \frac{\partial E \Pi}{\partial b_{i}(\bar{s}, \bar{s})}=\left(2 \alpha \pi-b_{i}(\bar{s}, \bar{s})-b_{-i}(\bar{s}, \bar{s})\right) \\
& \times\left(\left(1+(1-s) e_{-i}\right) \frac{\partial e_{i}}{\partial b_{i}(\bar{s}, \bar{s})}+\left(1+(1-s) e_{i}\right) \frac{\partial e_{-i}}{\partial b_{i}(\bar{s}, \bar{s})}\right) \\
& \underbrace{+\frac{\partial E U^{J p}}{\partial b_{i}(\bar{s}, \bar{s})}}_{\geq 0}=0, \quad \forall i,-i,
\end{aligned}
$$


with $e_{i}=\frac{b_{i}(\bar{s}, \bar{s})\left((1-s) b_{-i}(\bar{s}, \bar{s})-1\right)}{(1-s)^{2} b_{i}(\bar{s}, \bar{s}) b_{-i}(\bar{s}, \bar{s})-1}$ and $e_{-i}=\frac{b_{-i}(\bar{s}, \bar{s})\left((1-s) b_{i}(\bar{s}, \bar{s})-1\right)}{(1-s)^{2} b_{i}(\bar{s}, \bar{s}) b_{-i}(\bar{s}, \bar{s})-1}$. Denote the solution to this problem as $b_{i}^{J p}(\bar{s}, \bar{s})$.

The first-order conditions with respect to the bonuses of the researchers in an R\&D joint venture after $m_{i}=\bar{s}$ and $m_{-i}=\emptyset$ can be written as

$$
\begin{aligned}
& \frac{\partial E \Pi}{\partial b_{i}(\bar{s}, \emptyset)}=\left(2 \alpha \pi-b_{i}(\bar{s}, \emptyset)-b_{-i}(\bar{s}, \emptyset)\right) \\
& \times\left(\left(1+(1-s) e_{-i}\right) \frac{\partial e_{i}}{\partial b_{i}(\bar{s}, \emptyset)}+\left(1+(1-s) e_{i}\right) \frac{\partial e_{-i}}{\partial b_{i}(\bar{s}, \emptyset)}\right)-\left(e_{i}+e_{-i}-(1-s) e_{i} e_{-i}\right) \\
& \underbrace{+\frac{\partial E U_{i}^{J p}}{\partial b_{i}(\bar{s}, \emptyset)}}_{\geq 0}=0,
\end{aligned}
$$

and

$$
\begin{aligned}
& \frac{\partial E \Pi}{\partial b_{-i}(\bar{s}, \emptyset)}=\left(2 \alpha \pi-b_{i}(\bar{s}, \emptyset)-b_{-i}(\bar{s}, \emptyset)\right) \\
& \times\left(\left(1+(1-s) e_{-i}\right) \frac{\partial e_{i}}{\partial b_{-i}(\bar{s}, \emptyset)}+\left(1+(1-s) e_{i}\right) \frac{\partial e_{-i}}{\partial b_{-i}(\bar{s}, \emptyset)}\right)-\left(e_{i}+e_{-i}-(1-s) e_{i} e_{-i}\right) \\
& \underbrace{+\frac{\partial E U_{i}^{J p}}{\partial b_{-i}(\bar{s}, \emptyset)}}_{\geq 0}=0,
\end{aligned}
$$

with $e_{i}=\frac{b_{i}(\bar{s}, \emptyset)\left((1-s) b_{-i}(\bar{s}, \emptyset)-1\right)}{(1-s)^{2} b_{i}(\bar{s}, \emptyset) b_{-i}(\bar{s}, \emptyset)-1}$ and $e_{-i}=\frac{b_{-i}(\bar{s}, \emptyset)\left((1-s) b_{i}(\bar{s}, \emptyset)-1\right)}{(1-s)^{2} b_{i}(\bar{s}, \emptyset) b_{-i}(\bar{s}, \emptyset)-1}$. Denote the solution to this problem as $b_{i}^{J p}(\bar{s}, \emptyset)$ and $b_{-i}^{J p}(\bar{s}, \emptyset)$.

Under symmetric information on $s$, the first-order conditions were

$$
\begin{aligned}
\frac{\partial \Pi^{J}}{\partial b_{i}}=\left(2 \alpha \pi-b_{i}-b_{-i}\right)\left(\left(1+(1-s) e_{-i}\right)\right. & \left.\frac{\partial e_{i}}{\partial b_{i}}+\left(1+(1-s) e_{i}\right) \frac{\partial e_{-i}}{\partial b_{i}}\right) \\
& -\left(e_{i}+e_{-i}-(1-s) e_{i} e_{-i}\right)=0, \quad \forall i,-i,
\end{aligned}
$$

with $e_{i}=\frac{b_{i}\left((1-s) b_{-i}-1\right)}{(1-s)^{2} b_{i} b_{-i}-1}$ and $e_{-i}=\frac{b_{-i}\left((1-s) b_{i}-1\right)}{(1-s)^{2} b_{i} b_{-i}-1}$.

Therefore, $b_{i}^{J p}(\bar{s}, \bar{s})>b_{i}^{J}, b_{i}^{J p}(\bar{s}, \emptyset)>b_{i}^{J}$, and $b_{-i}^{J p}(\bar{s}, \emptyset)>b_{-i}^{J}$. That is, with private information on synergies, the incentives given to the researchers in an R\&D joint venture are higher than with symmetric information on synergies. Note that conflict 1 occurs for relatively high levels of the monopoly profit. 
Now determine whether it is profitable to implement truthful revelation. Clearly, for $\bar{s}$ close to $s(\pi)$, for which $\Pi^{J}=\Pi^{S}$, this is not the case, whereas for $\bar{s}$ close to $s(\pi)$, for which $U^{J}=U^{S}$, it is. Hence, $b_{i}^{S p}(\emptyset) \leq b_{i}^{S}, b_{i}^{J p}(\bar{s}, \bar{s}) \geq b_{i}^{J}, b_{i}^{J p}(\bar{s}, \emptyset) \geq b_{i}^{J}$, and $b_{-i}^{J p}(\bar{s}, \emptyset) \geq b_{-i}^{J}$.

\section{Proof of Proposition 4}

Proof. Suppose first that the principal implements truthful revelation. With contracts that induce the researchers to reveal their signal if they received one, the expected profits are as follows. With probability $(1-q)^{2} \theta$, neither researcher received a signal, it turns out that $s=\bar{s}$, and the profits are $E \Pi^{J p}(\emptyset, \emptyset, \bar{s})$. With probability $(1-q)^{2}(1-\theta)$, neither researcher received a signal, it turns out that $s=\underline{s}$, and the profits are $E \Pi^{J p}(\emptyset, \emptyset, \underline{s})$. With probability $q^{2} \theta$, both researchers received $s=\bar{s}$, which they have an incentive to reveal, and the profits are $E \Pi^{J p}(\bar{s}, \bar{s}, \bar{s})$. With probability $2 q(1-q) \theta$, only one researcher received $s=\bar{s}$, which he has an incentive to reveal, and the profits are $E \Pi^{J p}(\bar{s}, \emptyset, \bar{s})$. With probability $q^{2}(1-\theta)$, both researchers received $s=\underline{s}$. In the equilibrium in which they reveal, both researchers receive a transfer for revealing, and the expected profits are $E \Pi^{S p}(\underline{s})-\left(E U_{i}^{J p}(\emptyset, \emptyset, \underline{s})-E U_{i}^{S p}(\underline{s})\right)$. With probability $q(1-q)(1-\theta)$, only the researchers of firm $i$ received $s=\underline{s}$. In the equilibrium in which he reveals his, researcher $i$ receives a transfer for revealing from the owner of his firm, and the expected profits of firm i's owners are $E \Pi^{S p}(\underline{s})-\left(E U_{i}^{J p}(\emptyset, \emptyset, \underline{s})-E U_{i}^{S p}(\underline{s})\right)$. Finally, with probability $q(1-q)(1-\theta)$, only the researchers of firm $-i$ received $s=\underline{s}$. In the equilibrium in which he reveals his signal, researcher $i$ does not receive a transfer for revealing from the owner of his firm. However, the owners of firm $-i$ will reject the R\&D joint venture, and the expected profits of firm $i$ 's owners are $E \Pi^{S p}(\underline{s})$. Therefore, the firms' 
expected profit is

$$
\begin{aligned}
& E \Pi=(1-q)^{2} \theta E \Pi^{J p}(\emptyset, \emptyset, \bar{s})+(1-q)^{2}(1-\theta) E \Pi^{J p}(\emptyset, \emptyset, \underline{s}) \\
& +q^{2} \theta E \Pi^{J p}(\bar{s}, \bar{s}, \bar{s})+2 q(1-q) \theta E \Pi^{J p}(\bar{s}, \emptyset, \bar{s}) \\
& +q^{2}(1-\theta)\left(E \Pi^{S p}(\underline{s})-\left(E U_{i}^{J p}(\emptyset, \emptyset, \underline{s})-E U_{i}^{S p}(\underline{s})\right)\right) \\
& +q(1-q)(1-\theta)\left(E \Pi^{S p}(\underline{s})-\left(E U_{i}^{J p}(\emptyset, \emptyset, \underline{s})-E U_{i}^{S p}(\underline{s})\right)\right) \\
& +q(1-q)(1-\theta) E \Pi^{S p}(\underline{s}) .
\end{aligned}
$$

The restrictions to be fulfilled are the limited liability constraints, the researchers' participation constraints, and the effort incentive compatibility constraints.

The first-order conditions for bonuses when at least one researcher received $s=\bar{s}$ are the same as before. Furthermore, because researchers do not have an incentive to hide $s=\bar{s}$, if both researchers sent $m_{i}=m_{-i}=\emptyset$ and, in an R\&D joint venture, it turns out that $s=\bar{s}$, the owners can conclude that there was no incentive problem. Hence, in this situation, the first-order conditions for the bonuses are the same as before. We get $\frac{\partial \Pi}{\partial b_{i}\left(m_{i}, m_{-i}, \bar{s}\right)}=\frac{\partial \Pi^{J}}{\partial b_{i}}$ and $b_{i}^{J p}\left(m_{i}, m_{-i}, \bar{s}\right)=b_{i}^{J}$.

Given that $q^{2}+2 q(1-q)=1-(1-q)^{2}$, each firm's first-order condition with respect to the bonus of the researcher employed in that firm in stand-alone can be written as

$$
\frac{\partial E \Pi}{\partial b_{i}(\underline{s})}=\left(1-b_{-i}(\underline{s})\right) \pi+b_{-i}(\underline{s}) \frac{\pi}{2}-2 b_{i}(\underline{s}) \underbrace{+\frac{q}{1-(1-q)^{2}} \frac{\partial E U_{i}^{S p}(\underline{s})}{\partial b_{i}(\underline{s})}}_{\geq 0}=0 .
$$

Denote the solution to this problem as $b_{i}^{S p}(\emptyset)$.

Under symmetric information on $s$, the first-order condition was

$$
\frac{\partial E \Pi^{S}}{\partial b_{i}}=\left(1-b_{-i}\right) \pi+b_{-i} \frac{\pi}{2}-2 b_{i}=0 .
$$

Thus, $b_{i}^{S p}(\emptyset)>b_{i}^{S}$, and with private information on synergies, the incentives given to the researchers in stand-alone are higher than those given with symmetric information.

Furthermore, given that $q^{2}+(1-q)=q$, the first-order conditions with respect to the bonus the researchers receive in an $\mathrm{R} \& \mathrm{D}$ joint venture if $m_{i}=m_{-i}=\emptyset$ if the synergies turn 
out to be $\underline{s}$ are

$$
\begin{aligned}
& \frac{\partial E \Pi}{\partial b_{i}(\emptyset, \emptyset, \underline{s})}=\left(2 \alpha \pi-b_{i}(\emptyset, \emptyset, \underline{s})-b_{-i}(\emptyset, \emptyset, \underline{s})\right) \\
& \times\left(\left(1+(1-s) e_{-i}\right) \frac{\partial e_{i}}{\partial b_{i}(\emptyset, \emptyset, \underline{s})}+\left(1+(1-s) \frac{\partial e_{-i}}{\left.\left.e_{i}\right) \frac{b_{i}(\emptyset, \emptyset, \underline{s})}{\partial b}\right)-\left(e_{i}+e_{-i}+(1-s) e_{i} e_{-i}\right)}\right.\right. \\
& \quad \underbrace{-\frac{q}{(1-q)^{2}} \frac{\partial E U_{i}^{J p}(\emptyset, \emptyset, s}{\partial b_{i}(\emptyset, \emptyset, \underline{s})}}_{\leq 0}=0, \quad \forall i,-i,
\end{aligned}
$$

with $e_{i}=\frac{b_{i}(\emptyset, \emptyset, \underline{s})\left((1-s) b_{-i}(\emptyset, \emptyset, \underline{s})-1\right)}{(1-s)^{2} b_{i}(\emptyset, \emptyset, \underline{s}) b_{-i}(\emptyset, \emptyset, \underline{s})-1}$ and $e_{-i}=\frac{b_{-i}(\emptyset, \emptyset, \underline{s})\left((1-s) b_{i}(\emptyset, \emptyset, \underline{s})-1\right)}{(1-s)^{2} b_{i}(\emptyset, \emptyset, \underline{\varphi}) b_{-i}(\emptyset, \emptyset, \underline{s})-1}$. Denote the solution to this problem as $b_{i}^{J p}$.

Under symmetric information on $s$, the first-order conditions were

$$
\begin{aligned}
\frac{\partial \Pi^{J}}{\partial b_{i}}=\left(2 \alpha \pi-b_{i}-b_{-i}\right)\left(\left(1+(1-s) e_{-i}\right)\right. & \left.\frac{\partial e_{i}}{\partial b_{i}}+\left(1+(1-s) e_{i}\right) \frac{\partial e_{-i}}{\partial b_{i}}\right) \\
& -\left(e_{i}+e_{-i}-(1-s) e_{i} e_{-i}\right)=0, \quad \forall i,-i,
\end{aligned}
$$

with $e_{i}=\frac{b_{i}\left((1-s) b_{-i}-1\right)}{(1-s)^{2} b_{i} b_{-i}-1}$ and $e_{-i}=\frac{b_{-i}\left((1-s) b_{i}-1\right)}{(1-s)^{2} b_{i} b_{-i}-1}$.

Thus, $b_{i}^{J p}(\emptyset, \emptyset, \underline{s})<b_{i}^{J}$; that is, with private information on synergies, the incentives given to the researchers in an R\&D joint venture if researchers hide the signal or if they did not receive one and the synergies turn out to be $\underline{s}$ are lower than the incentives given with symmetric information. Note that conflict 2 occurs for intermediate levels of the value of the monopoly profit.

Now check whether it is profitable to implement truthful revelation. Clearly, for $\bar{s}$ close to $s(\pi)$ for which $\Pi^{J}=\Pi^{S}$, this is not the case, whereas for $\bar{s}$ close to $s(\pi)$ for which $U^{J}=U^{S}$, it is. Hence, $b_{i}^{S p}(\emptyset) \geq b_{i}^{S}$ and $b_{i}^{J p}(\emptyset, \emptyset, \underline{s}) \leq b_{i}^{J}$. 